\title{
Standardisation in Mapping and Monitoring of Invasive Alien Plant Species
}

\author{
J. M. K. Kandeh ${ }^{*}$ and L. Kumar ${ }^{2}$ \\ ${ }^{1}$ UNDP AIMS, P.O. Box 5, Foreign Ministry Road, Kabul, Afghanistan \\ ${ }^{2}$ Department of Ecosystem Management, School of Environmental Sciences and Natural Resources Management, \\ University of New England, Armidale NSW 2351, Australia
}

\begin{abstract}
The control and eradication of invasive alien plants in South Africa where about 10.1 million hectares of land has been invaded requires information about their extent and distribution. In this study it has been shown that in order to effectively and economically control invasive alien plants in the St. Lucia Heritage Site, the Working for Water organisation requires data on the extent and distribution of invasion not only of its operational areas but also of the surrounding areas. Information on extent and distribution requires the compiling data from multiple sources. Multi source data integration has been shown to be a troublesome exercise due to differences in methods in data acquisition, representation, coding, classification, scales, map projections, and mapping formats. Such data integration can only be made possible when organizations with a common goal adopt a common approach that would facilitate sharing data and information. In this study it has also been shown that multi-source alien species data integration and comparability of data amongst organizations was made possible through the adoption and successful implementation of data formats, data exchange, and user design standards. It has also been shown that mapping the extent and distribution of invasive alien plants requires the development of a geographic information system known as the Alien Plants Management Information System (APMIS). APMIS integrates data from multiple sources through the development and adoption of standards known as Geocode. Geocode is made up of the Land Mapping Unit (known as NBAL) and a date field so that both the spatial and temporal state of alien distribution and eradication can be recorded. This coding standard does not only indicate which location and time a species was found but also ensures comparability over time on how the distribution and eradication was progressing. The Geocode (NBAL + Date) can be very useful in modelling both the spatial and temporal variability of land mapping units and can be applicable in the areas of agricultural weed eradication programmes and in complex humanitarian environments where multiple organizations need to share data.
\end{abstract}

Keywords: Biological diversity, invasive alien plants, Geographic Information Systems, standards, systems development methodology

\section{Introduction}

Alien plant invasions are getting more widespread and serious at an alarming rate around the world. Many more species are becoming invasive, more processes are being disrupted, more ecosystems damaged, and more costs are being incurred (Richardson et al., 2004). Invasive alien plant species pose threats to both natural and managed ecosystems and a serious threat to biodiversity (Holmes and Cowling, 1997) and also lead to economic consequences (Simberloff, 1996; Myers et al., 2000). This growing worldwide habitats destruction is a product of human induced transfer of organisms either intentionally or accidentally through trade and colonization (WRI, 1999; Mack et al., 2000). By definition, the "Invasive or alien species are species, subspecies or lower taxon occurring outside of their natural range and dispersal potential and includes any part or gametes of such species that might survive and subsequently reproduce" (Turlings, 2000).

Due to their serious environmental consequences, invasive alien species have become a major conservation problem both at national and international levels (WRI, 1999; UNEP,

\footnotetext{
* Corresponding author: joseph.kandeh@undp.org
}

CBD and SBSTTA, 2001). As such several attempts to control and eradicate invasive species have been initiated (Groves, 1989; Usher, 1989; Muniappan and Marutani, 1996; Myers et al., 2000).

The spread of alien species has become an issue of international importance. Their global impact has been recognised in the convention on Biological Diversity, which calls for the control and monitoring of exotic species that threaten ecosystems, habitats and species (UNEP, 1994). It also recognised the need to establish information systems that compile data on species that have significant environmental impacts.

South Africa's natural ecosystems, like those in most parts of the world, are under threat from invasive alien plants (Macdonald et al., 1986; Richardson et al., 1997). The scale of the problem facing managers of invasive alien plants in South Africa is huge; about 10 million hectares have been invaded to some extent (Le Maitre et al., 2000). The invasion affects the economy of the country, the environment and also the lives of South Africans either directly or indirectly.

Many invaders are already well-established, while scores of others are at early stages of invasion. Several are recent introductions, and/or have only recently entered a phase of rapid population growth (Nel et al., 2004). The invasive plants were introduced into South Africa from various countries: 64 
species were introduced from South and Central America, 14 from North America, 26 from Australia, 19 from Europe, and 25 from Asia (McQueen and Noemdoe, 2000). Various reasons have been given for their introduction in South Africa. The reasons range from: as crop species, for timber and firewood, as garden ornamentals, for sand dune stabilisation, as barrier and hedge plants and also through the accidental abandonment of cargo in the Port of Durban in the 1940s. Today many of these plants have survived the South African landscape on their own, whilst some have become invasive (McQueen and Noemdoe, 2000).

There are 161 species (38 herbaceous, 13 succulent and 110 woody) that have been introduced into South Africa and classified as invasive, although it is estimated that many more will become weeds in time (McQueen and Noemdoe, 2000). Some of the invasive species are the Monterey pine from the United States of America, gums, wattles and hakea from Australia, and Lantana and Chromolaena from South America.

South African scientists have recognized the potential impacts of invasive alien plants on indigenous vegetation (Stirton, 1978; Macdonald et al., 1986) and the ecological services that could be lost as a result of the invasion (Higgins et al., 1997; Van Wilgen et al., 1997). In responding to the convention on Biological Diversity (UNEP, 1994), South Africa calls for the control and monitoring of exotic species that threaten ecosystems, habitats and species. In order to do this it requires the need to establish information systems that compile data on invasive alien plant species.

Data on invasive alien plants in most parts of the country are very weak and hence do not produce a comprehensive picture of alien plants invasion in the country. In the Greater St. Lucia Wetland Park of KwaZulu-Natal province, the South African Government is implementing a mapping and control programme on invasive alien plant species through The Working for Water Programme (WFW). The Greater St. Lucia Wetland Park is a World Heritage site (UNESCO, 1999). Bordering the heritage site are vast tracks of land owned by forest plantation companies, sugar cane farmers, private landowners and village communities. The entire area has been invaded by alien plant species. Drake et al. (1998) provided evidence that the seeds of Chromolaena odorata, one of the prominent invasive alien plants in South Africa, can travel up to $80 \mathrm{~km}$ when dispersed. Thus the successful control of alien plants in the Heritage Site would have to consider extent and distribution of alien plants in the neighbouring lands.

The organisations and groups of people (Table 1) are aware of the environmental impact of alien plants. Identification and control of alien plants is a priority to them. Each entity has a department or unit that deals with the identification and control of alien plants and each year each entity spends a substantial amount of money on eradication of alien plants. The lack of a national policy on collaboration and data sharing has resulted in poor success in the control and eradication of alien plants, making the entire government programme (WFW) more of the employment creation programmes than a control and eradication one.

Mapping and monitoring invasive alien plants in South Africa requires knowledge on their spatio-temporal distribution. This requires integrating data on alien species from a variety of sources, either through the development of new standards, or the adoption or adaptation of standards regarding data acquisition, data coding, classification, processing, and management to facilitate the data exchange. It also requires willingness on part of stakeholders to cooperate, coordinate, and standardise their activities.

This paper discusses how mapping, control and eradication of invasive alien plants can be effective through the cooperation, coordination, collaboration, and standardisation amongst stakeholders. It further discusses how the development, adaptation and adoption of standards in a GIS community of government departments, forest companies and farmers can enable the integration of data on invasive alien plants from multiple sources.

\section{Methodology}

\subsection{Study Area}

The study area is located in The Greater St. Lucia Wetland Park of KwaZulu Natal province of South Africa (Figure 1). The Greater St. Lucia site consists of thirteen contiguous protected areas with a total area of 234,566 hectares. The site is the largest estuarine system in Africa and includes the southernmost extension of coral reefs on the continent. The site contains a combination of on-going fluvial, marine and Aeolian processes that have resulted in a variety of landforms and ecosystems. Features include wide submarine canyons, sandy beaches, forested dune cordon and a mosaic of wetlands, grasslands, forests, lakes and savannah. The variety of morphology as well as major flood and storm events contribute to the ongoing evolutionary processes in the area. Natural phenomena include shifts from the low to hyper-saline states in the Park's lakes; large numbers of nesting turtles on the beaches; the migration of whales, dolphins and whale-sharks off-shore; and huge numbers of waterfowl including large breeding colonies of pelicans, storks, herons and terns. The Park's location between sub-tropical and tropical Africa as well as its coastal setting has resulted in exceptional biodiversity including some 521 bird species (UNESCO, 1999).

The St. Lucia Park is situated in the coastal lowland bio-climatic zone (Taylor, 1982) between latitudes $27^{\circ} \mathrm{S}$ and $29^{\circ} \mathrm{S}$. The area covers False Bay, West and Eastern Shores, The Estuary, Futululu State Forest, and Mapelane. Current land use of the St. Lucia Park is for nature conservation together with nature-based tourism. Land-use in adjoining areas is large-scale irrigated sugarcane and plantation forests owned by Mondi, SAFCOL and SAPPI.

\subsection{Requirements Analysis}

The information requirements of the users were determined by conducting a survey of senior managers, plantation 
Table 1. Organizations Involved in Eradicating Invasive Alien Plants in the Heritage Site

\begin{tabular}{ll}
\hline Name of Organisation/Group & Mandate \\
\hline $\begin{array}{l}\text { Forest Companies of Mondi, SAFCOL, } \\
\text { and SAPPI }\end{array}$ & $\begin{array}{l}\text { Possess large areas of cultivated land with plantation forest for pulpwood and timber } \\
\text { production. Their operational areas are spread over the entire country. }\end{array}$ \\
Sugar Cane Farmers & To maximise production from the farms, and ensure weeding of invasive alien plants. \\
ESKOM & $\begin{array}{l}\text { The national electricity company responsible for providing electricity to the entire country. } \\
\text { Their transmission lines are spread across the landscapes of the country and have to be kept } \\
\text { clean of vegetation except endangered plant species. }\end{array}$ \\
TELKOM & $\begin{array}{l}\text { The national telephone company with telephone lines traversing the landscapes. These lines } \\
\text { have to be kept clean of vegetation except endangered plant species. }\end{array}$ \\
Rept. of Roads & $\begin{array}{l}\text { Responsible for maintenance of roads in the country. Invasive alien plants are often seen } \\
\text { alongside the roads, thus the Department's interest is to see that the roads are kept clean }\end{array}$ \\
through brushing. & $\begin{array}{l}\text { The Government of South Africa through CARA mandates the removal of alien plants from } \\
\text { the landscapes of South Africa. Productive lands should be clean of alien plants, and those that } \\
\text { have been invaded, should be cleared. }\end{array}$ \\
Dept. of Agriculture & $\begin{array}{l}\text { Land targeted for distribution under the land reforms programme is cleared of invasive alien } \\
\text { plants. }\end{array}$ \\
Ensures that human settlements are clear of invasive alien plants. \\
Drimary focus is to promote sound environmental programmes affecting their communities \\
thereby ensuring the implementation of CARA.
\end{tabular}

managers, environmental managers and silviculturists from two of the forest companies, and the conservationists and GIS personnel of the research unit of the KZN Wildlife office in the St. Lucia Office and in the Hluhlwei Game Reserve. Those also interviewed were the executive members of the Nyalzi Conservancy and the head of the technical services of the Mtubatuba Municipality. In addition, the head of the Leopard Mountain Game Lodge (a local non-governmental organisation) close to Nkuzi was interviewed.

At WFW Greater St. Lucia Wetland Project, the following persons were interviewed: the GIS and mapping officer, the programme manager, the assistant manager, two of the contractors, and some members of one of the team contractors. In addition, the project leader and the GIS officer from the regional office of Working for Water Programme in PieterMaritzburg were also interviewed. Also interviewed persons were some members of the Plant Protection Research Institute, which undertakes research into the biological control of Chromolaena odorata with funding received from WFW. The large numbers of stakeholders were interviewed in order to explicitly define the requirements of an integrated APMIS. This was done to ensure that the new system captured the needs of all key players interested in the identification and control of invasive alien plants in the Greater St. Lucia Wetland Park. In each interview, the users were asked:

1) To define their management objectives;

2) To identify the tasks carried out to achieve their management objectives;

3) To identify the tasks carried out in the identification and control of invasive alien plant species;
4) To identify the decisions made in planning and executing the tasks of identifying and controlling alien plants;

5) To identify the information they needed in making their decisions on the alien plants control and the sources of their data; and

6) Review of the organisational policies relating to data acquisition, data exchange, data quality and data standards.

\subsection{Mapping Invasive Alien Plants Species}

In the St. Lucia Wetland Park there are three major players in the control of alien plants: WFW, Mondi and the Kwazulu Natal Wildlife (KZN Wildlife). Due to time constraints, it was decided to prototype APMIS primarily focussing on the three major players. The methods used by the three organisations in mapping alien plants differed considerably. This has resulted in the lack of a consistent method in data acquisition and data not being in a standardised format, thus making direct comparison extremely difficult.

\subsubsection{The WFW Approach}

The approach and methodology adopted by WFW derives greatly from the method of Le Maitre and Versfeld (1994) developed for mapping aliens at a 1:50,000 scale for a Fynbos catchment management system. Such a methodology depends on observable features of the species. It provides data, which forms the basis for the calculation of water use, total cost of clearing an invaded area, the man days required to clear a piece of invaded land, the control method to be used, 


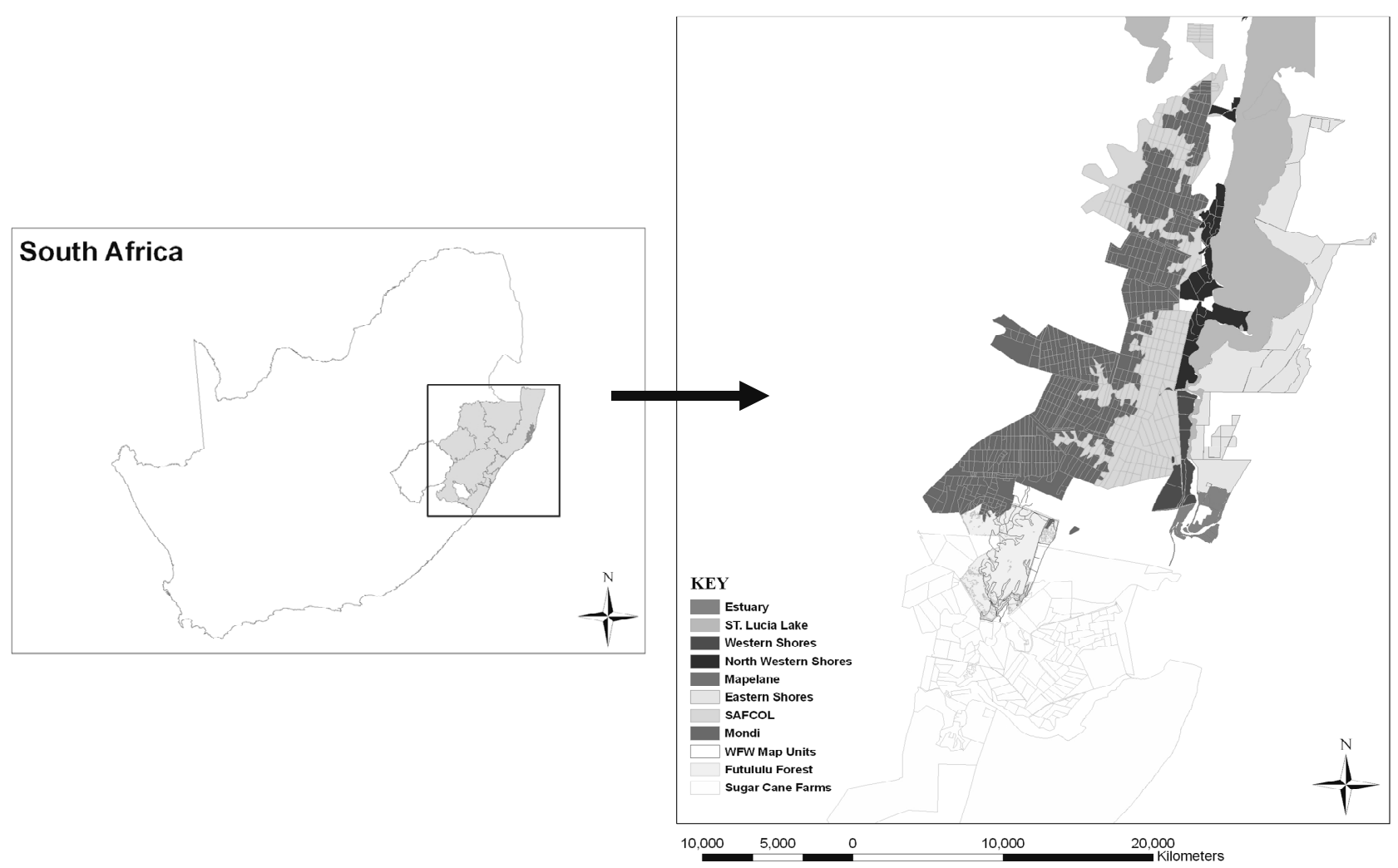

Figure 1. Location of study area.

quantity of herbicides, and the required equipment. Such a method is also capable of mapping easily distinguishable growth forms ranging from herbaceous to shrubs and trees.

The minimum data required for each invaded area are species, plant canopy (\%) or density, plant size and habitat type. Mapping is according to the following guidelines:

1) Map scale for a management plan of WFW is typically $1: 50,000$ to $1: 10,000$.

2) Primary task of WFW is the clearing of invasive alien plants from an invaded area, through the award of a contract to a contractor.

3) Prior to the generation of a contract, the Programme Manager undertakes a field survey of the management units selected for clearing and records the species found, the density class of each species, the age of the species, and the growth stage of the species. In addition, the following habitat features are also recorded: the slope, approximate flat area and the habitat type (riparian or landscape).

4) The attribute data on each invaded area from the field survey will be entered in the Working for Water Management Information System (WIMS), which links it to the spatial data.

5) Based on the field survey report, a GIS and Mapping Officer generates a contract map showing areas requir- ing clearing.

6) The contract map is issued to contractors who need to know the areas to work, the alien species present, the degree of infestation, and the man-days required to complete the task.

7) The Le Maitre and Versfeld (1994) methodology uses density/cover classes of the alien plants as a basis for mapping and decision making.

8) When a mixture of species is found in an area, as is often the case, the density/cover classes are recorded separately for each species in the mixture.

9) Based on the Le Maitre method, seven density classes are used when mapping. They include: (a) Rare, (b) Occasional, (c) Very scattered, (d) Scattered, (e) Medium, (f) Dense, and (g) Closed.

10) Information on the size and growth form of the species (seedlings, young, or adult) is also recorded. This information is recorded as it has been found that the size and reproductive maturity of the invading alien plants can have a substantial impact on both the cost of treatment and the type of treatment required.

11) Information is also recorded about the location of the invasion (riparian or non-riparian) as these have been shown to differ in species composition, density, and water use, which is useful for hydrological modelling. 


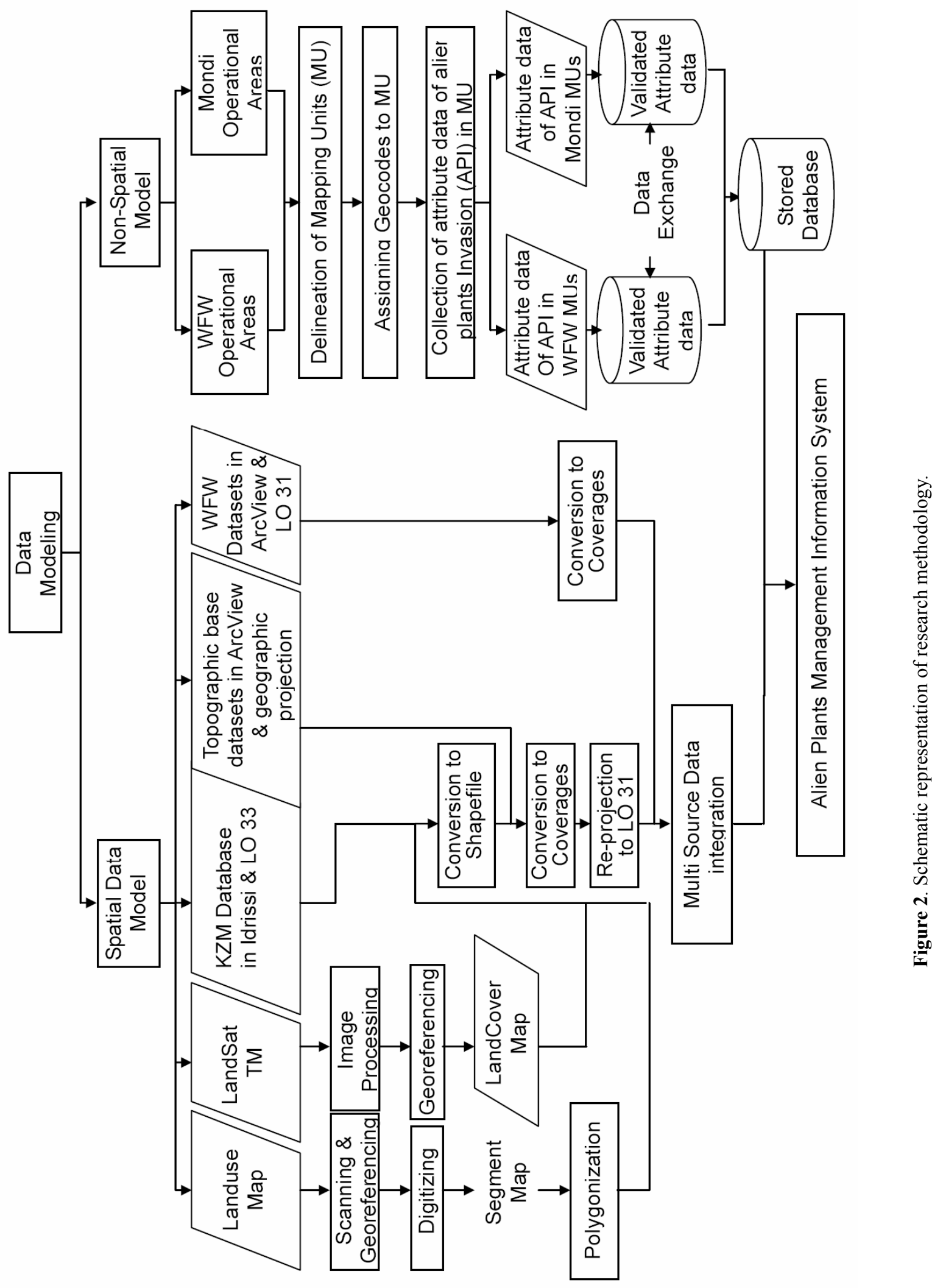


12) The Wetland project does not map watercourses invaded with alien plants.

13) Invasive plants clearing commences with an initial clearing, followed by a series of follow-ups spanning a period of three months between the follow-ups. A maximum of six follow-ups can be undertaken depending on the invaded area.

14) Both spatial and the non-spatial data are stored in a GIS (Arcview 3.2a).

15) Spatial data are in the following projection parameters: Transverse Mercator projection, Clark 1880 spheroid, Central Meridian of 31, and a Scale Factor of 1.

\subsubsection{Approach of Mondi Forest Company}

The management goals of the forest companies differ from WFW, their interest being to increase production of quality timber, the pulp and other products. The Pinus and the Eucalyptus are the predominant species grown in the plantation forests of South Africa. These tree species have been classified as aliens, though placed in Category 2, which gives the companies the right to plant them only with permission from the government. In areas outside the plantations, the tree species are cleared from the terrain like any of the Category 1 alien plants.

The promulgation of the Conservation of Agricultural Resources Acts (CARA, 43 of 1983) stipulates plants that must be removed from the land (Category 1), plants that can only be grown with a permit (Category 2) and plants that may not be sold or propagated (Category 3 ). Invasive alien plants besides the Pinus and Eucalyptus species growing on compartments of the plantation forests are declared as weeds, and thus must be eradicated within the first three years. The process of ensuring that the compartments and the surrounding land are cleared of alien plants is the responsibility of the Department of Silviculture. The department has the budget to plan weed eradication from the operational areas of the company every year. It hires contractors for weed eradication and provides the necessary input in the form of equipment, herbicides and the requisite training in the various treatment methods. Invasive alien plants control at Mondi, like that of WFW, follows a sequence of clearings, ranging from initial clearing and followed by a series of follow-ups spanning a period of three months between the follow-ups. Costing the clearing per compartment depends on the density cover of alien plant species.

Forest companies do not record the presence and density cover of alien plants, and hence they are not involved in mapping these. Spatial data on invasive alien plants is lacking. However, they do recognise that density cover of alien plants is very useful in decision making relating to clearing and costing. Very few density classes are found in their classification; it is either sparse, or medium, or dense. Density cover below $25 \%$ is considered sparse, greater than $25 \%$ but less than $50 \%$ is considered medium and density cover greater than $50 \%$ is considered dense.
GIS analyses are out-sourced to a GIS firm that normally produces maps showing cadastre plots of the forest plantations. The Mondi, like most of the forest companies, do not allow access to digital datasets of cadastre plots of their forest plantations.

\subsubsection{Approach of KZN Wildlife}

Management for the World Heritage Site is normally the responsibility of KZN Wildlife. They receive funding from the Department of Environmental Affairs and Tourism (DEAT) through WFW for the rehabilitation of wetlands. While they are not involved in mapping alien plants species directly, they provide technical and managerial support to WFW in the conduct of the invasive alien plants mapping and control programme. They also have the expertise in identifying new species of alien plants within the Wetland Park.

\subsection{System and Problem Analysis}

All three organisations were examined in terms of their goals, organisational framework, and the operational environment in which they work. Detailed systems analysis revealed several problems. The core problem with the current alien mapping and control programme is the lack of adequate information on extent and distribution of invasive alien plants.

In addition, other problems identified included:

- The current mapping and control programme of WFW in The Greater St. Lucia Wetland project is only limited to the World Heritage Site.

- There is limited documentation of infestations of alien plants in the region, especially in areas outside WFW operational areas.

- Greater emphasis of the WFW project is on job creation rather than on eradication of alien plants.

- There is very little or no collaboration and networking between WFW in the Greater Saint Lucia Wetland project and its neighbouring organizations and local communities.

- There is a lack of standards in methods for data collection, representation, storage, management and data dissemination amongst the different groups. This makes it difficult for data comparability between the different organisations.

- The current management information system does not collect information on other environmental factors like soil characteristics, climate, biotic factors, and topography necessary to determine the ecological preferences of the invasive alien species.

- There are differences in GIS software and projections used by the various organisations, making data exchange difficult.

- There are indications of re-infestations taking place in WFW areas, which have been cleared, attributing the re-infestation to areas outside the WFW operational ar- 
eas.

- Government funding is gradually being reduced, thus necessitating the need for other key players with access to other funding sources to come forward.

\subsection{System Design}

Using the Waterfall Life Cycle Systems development methodology, a prototype system was developed known as Alien Plants Management Information System (APMIS). Figure 2 shows a schematic representation of the methodology used in developing APMIS. APMIS is a structured database on top of a core GIS-based system. This phase focussed on designing the database and the GIS system to handle both spatial and non-spatial data respectively. It specified the hardware and software necessary for implementing the proposed system. The interfaces, applications and documentation for the system were also developed. The three-tier database architecture as proposed by the ANSI/SPARC Study Group on Database Management Systems in 1978 was used.

\subsection{Prototype System Testing and Realisation}

It should be pointed out that developing a full blown system covering all the key players and the entire study area was not covered in this study. However, a prototype on a smaller scale was developed and tested. This involved building and integrating both the Database and the GIS system. In addition to documenting the system, implementation issues were also addressed in terms of the architecture of the prototype system, data collection, data quality and data exchange mechanisms.

\subsection{Spatial Data Modeling}

Using ILWIS 3.0*, a Landsat TM image (October 1999) of the study area was geo-referenced using Ground Control Points (GCPs). A total of 15 GCPs were collected that corresponded to the same points on the satellite image. Out of the 15 GCPs one contributed to a high root mean square (RMS) error and was then deleted, and a final RMS value of 0.668 was obtained. A land cover map was generated from the geo-referenced and geometrically corrected Landsat TM image (bands 4, 5, 3) using the maximum likelihood classifier of the supervised classification module. Training information was obtained from the topographic map of the area.

Existing land use map of the forest plantations, sugar cane farms and other land surrounding the heritage site was also scanned and geo-referenced using the same method as applied to the satellite image. Both land cover and land use datasets in ILWIS format were then converted to shapefiles (Arcview generic format) to enable them to be integrated with the rest of the datasets (particularly those of WFW) that were in shapefile formats.

All datasets were then converted into coverages and

\footnotetext{
* ILWIS 3.0 is a is a registered trademark of International Institute of Geoinformation Science and Earth Observation (ITC).
}

re-projected in to the same map projection (Transverse Mercator projection, Clark 1880). All conversion to coverages and re-projection were done using ArcInfo 8.1**. Using GIS overlay, the multi source data was integrated using Arview 3.2a.

In this study, defining Land Mapping Units (LMU) of both WFW and Mondi was not carried out as both operational areas were already partitioned into management plots. To model the temporal state of alien distribution and eradication, a composite unique identification code known as Geo-code made up of the NBAL and the date was used. This coding standard does not only indicate which location and time a species was found but also ensures comparability over time on how the distribution and eradication represented by the number (level) of treatments was progressing. All mapped units were assigned unique Geocodes. Attribute data was linked to the LMU through the Geocode. Geocode also differentiates between operational areas of the different organisations and the different water catchment areas.

\section{Results}

\subsection{Stakeholders and Their Interests}

The analysis revealed that alien plants are a threat to both natural and managed ecosystems, and also threaten biodiversity. Stakeholders are aware of the environmental impact of invasive alien plants and realise that their control from the landscapes of their operational areas is a priority not only locally but also at the national level. Examination of their requirements showed similarity although the same information was often used differently.

All organisations/groups had the following requirements:

- The need to identify areas within their operation areas that are invaded with alien plants. This information is required to determine overall priorities.

- The need to differentiate between the different types of alien plants, their growth forms, and their density cover.

- Information relating to habitat characteristics of invaded areas.

- To create jobs for clearing invasive alien plants using standard methods based on density cover and growth stage.

- Information relating to successful management of any control programme.

- To be able to assess the status of the clearing programme.

- To determine the costs involved in clearing aliens.

Requirements Analysis performed revealed that for the three major organizations, the map scale for a management plan is typically $1: 50,000$ to $1: 10,000$. Both WFW and Mondi needed information that differentiated between the different types of alien plants, their growth forms and their density cover. Both organizations used density cover as a variable to characterise alien plants invasion.

\footnotetext{
** ArcInfo 8.1 and Arview 3.2a are registered trademarks of ESRI.
} 

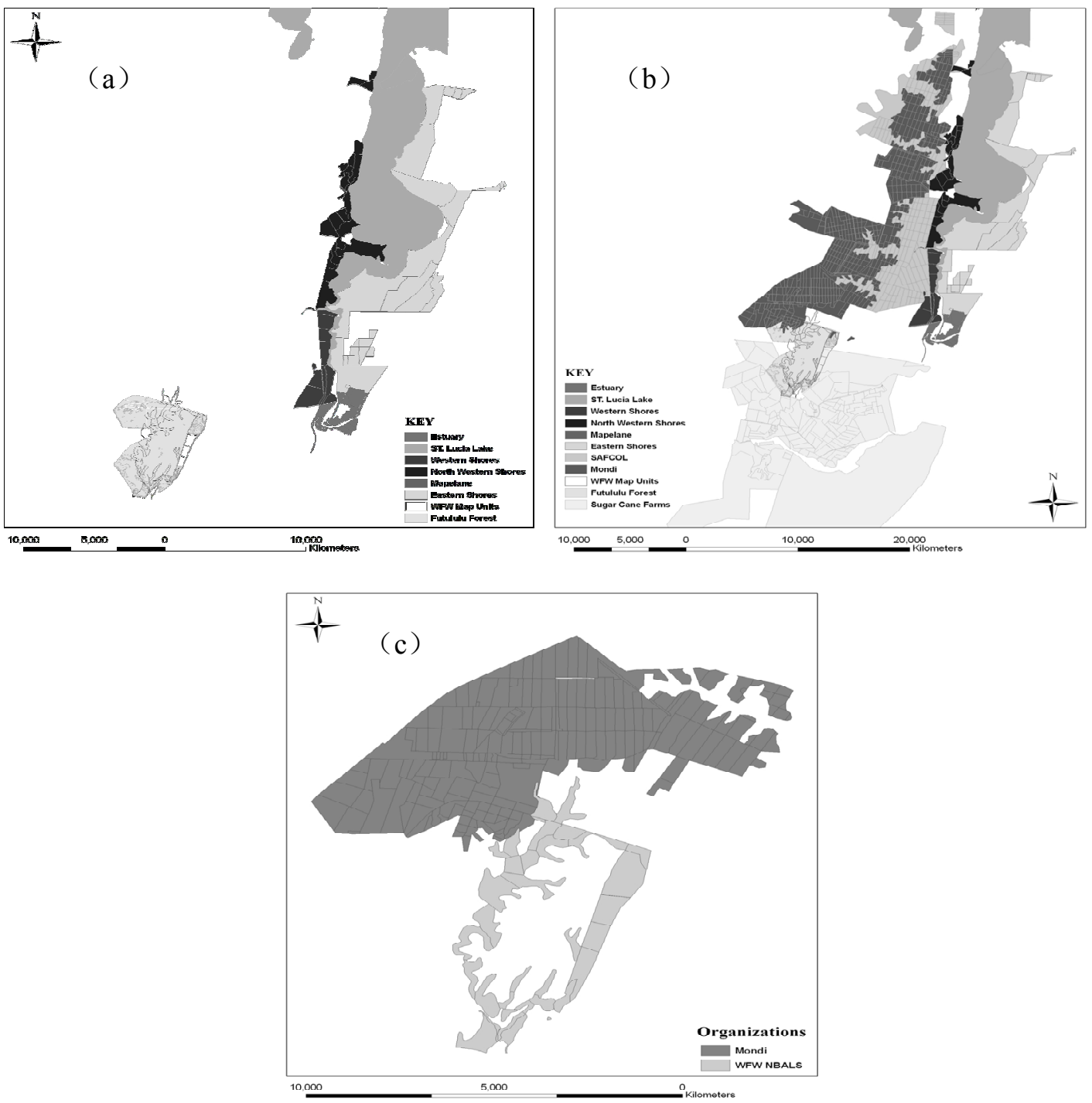

Figure 3. Information of (a) current mapping area (WFW operational areas), (b) entire area to be covered by the complete system, and (c) area covered by the prototype system.

Standards adopted include the following:

- To produce a 1:50,000 scale map and effectively compare data based on density cover of alien plants. The minimum size of a mapped unit should not be greater than $100 \mathrm{hec}-$ tares.

- Assigning the NBAL ID to each mapped unit whether invaded or not. NBAL is keeping in conformity with the database naming convention of the Department of Water and Forestry (DWAF) and WFW in South Africa.

- Assigning a Time Stamp to each mapped unit whether invaded or not.

- A Geo-Code composed of both NBAL ID and the Time Stamp to uniquely identify the land map unit, and to describe the state of alien distribution and eradication over time.

- Adoption of the methodology of Le Maitre and Versfed (1994) for mapping alien plants at a 1:50,000 scale.

- Based on the requirements analysis, the minimum required attribute data for an invaded area are species type, plant canopy (\%) or density and plant size.

- Use of four density cover classes in mapping alien plants invasion.

Requirements Analysis further revealed the need for three major map products: density distribution, eradication, and a contract map showing mapped units to be cleared. Figure 3 shows the current areas mapped, the entire area to be mapped, and the area covered by the prototype system. Figures 4 and 5 show assigning of NBAL code and geocode to mapped units 


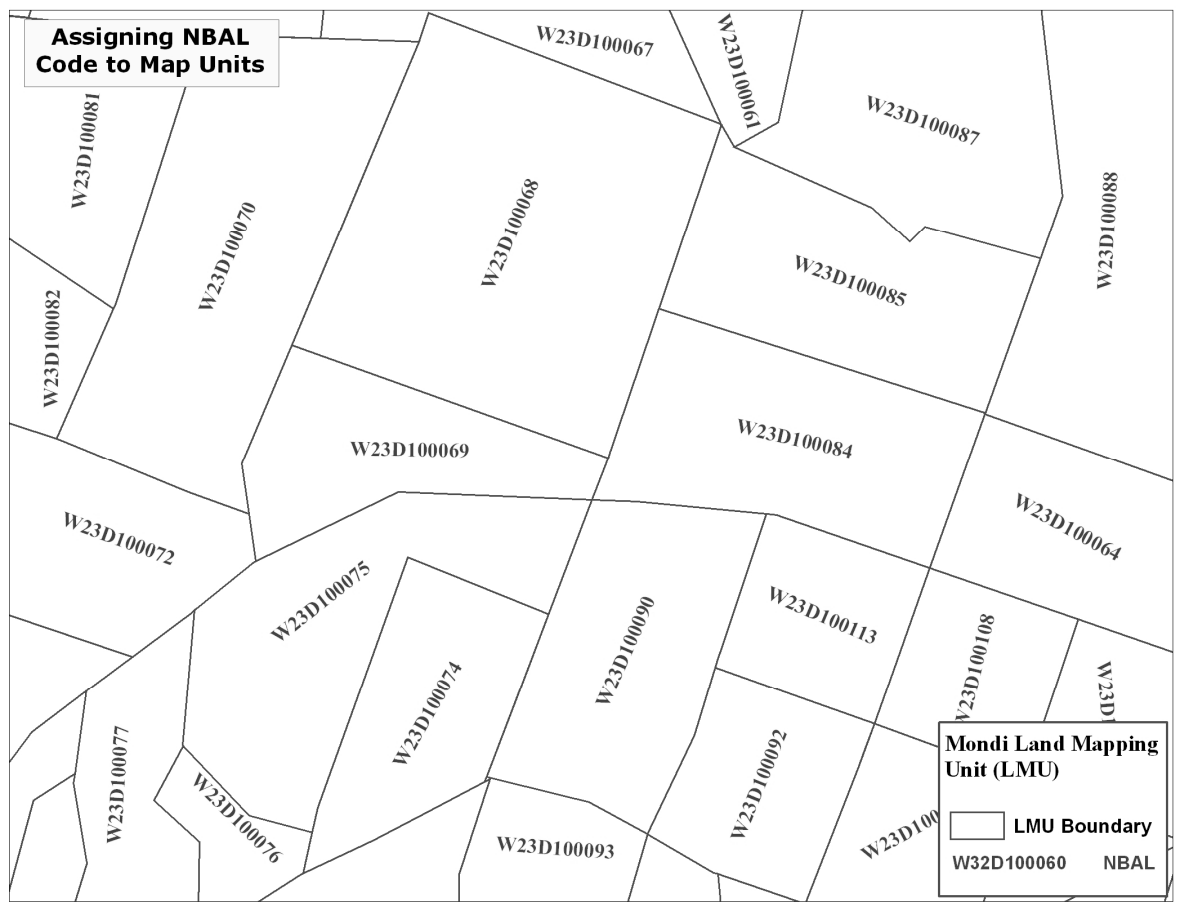

Figure 4. Assigning NBAL code to map units.

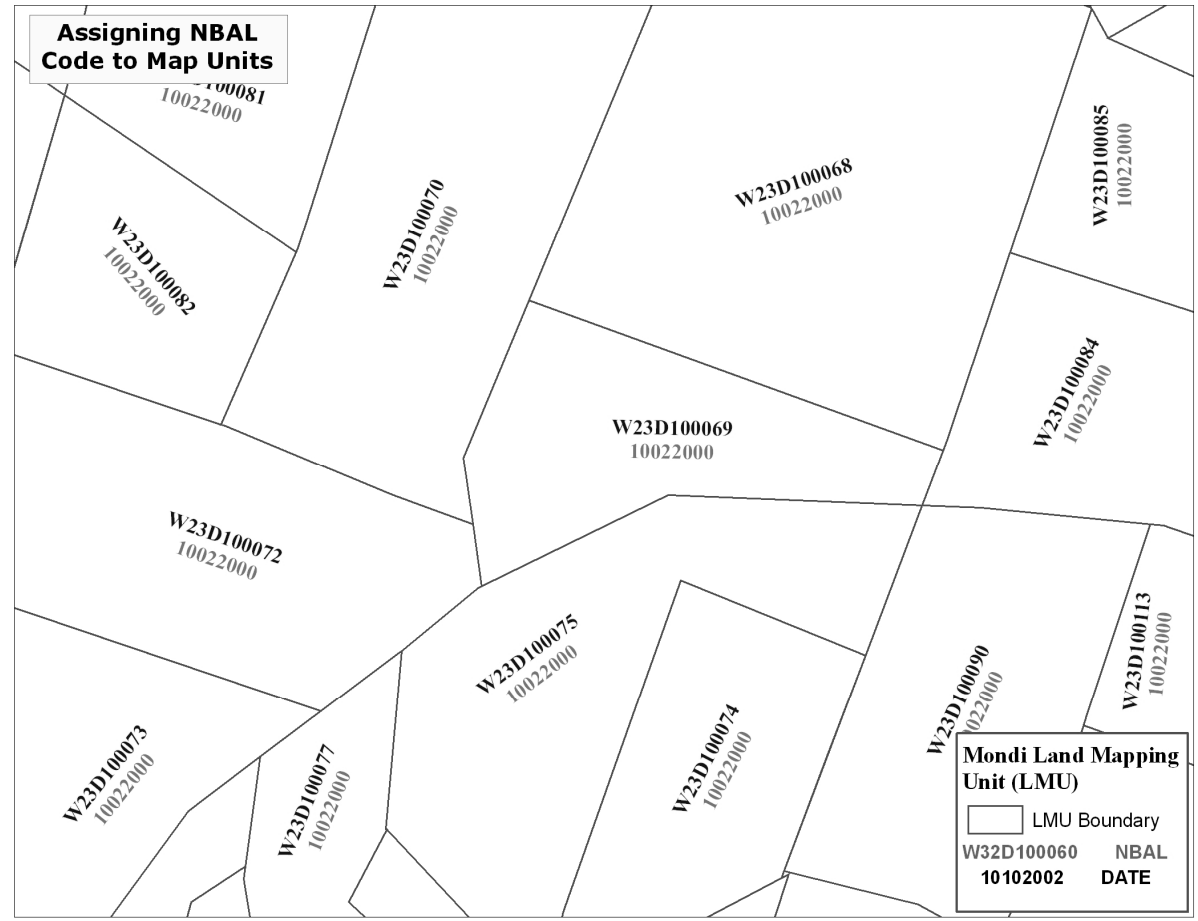

Figure 5. Assigning Geocode (NBAL + Date) to map units. 

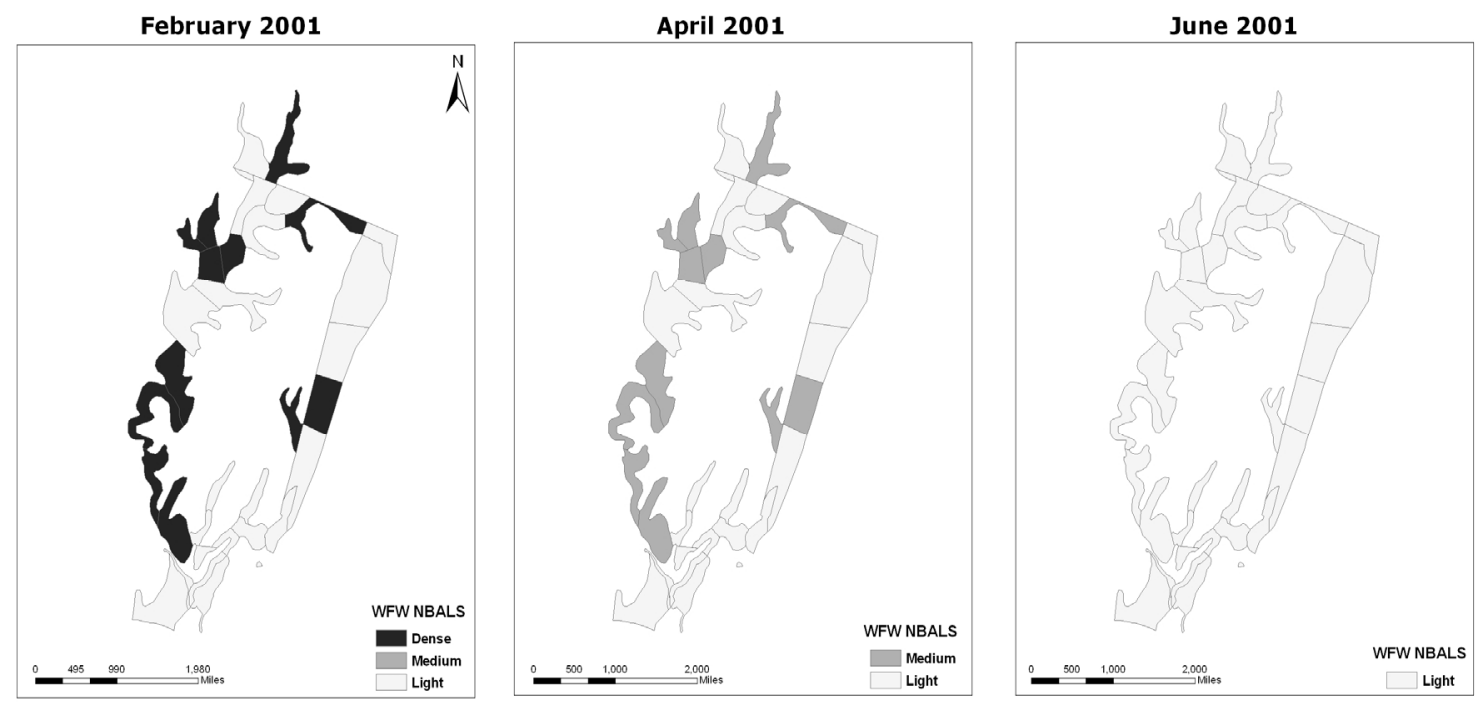

Figure 6. Monthly density distribution map of C. odorata in WFW areas.

of the Mondi Forest Plots. Based on the four density classes, Figure 6 shows monthly density distribution of C. odorata in WFW areas.

\subsection{Description of the Prototype System}

The prototype system is made up of both spatial and non-spatial data in ArcView 3.2a and MS Access 2000 respectively. The spatial data includes a mapping unit located in the terrain, which may or may not be invaded by alien plant species. Other spatial data includes linear features such as road networks, water bodies and river systems.

The spatial data layers are created through digitizing the existing maps, air photos and field mapping. The non-spatial data included thematic attributes of map units such as the slope percentage, soil type, accessibility, habitat type and altitude. The thematic attributes of alien plant species are also captured and these include their density, cover, plant size, species type, locality, observer and date of observation.

Attribute data are also captured on the process of clearing aliens from invaded areas, the number of times clearing has taken place (Figure 7), who was contracted to do the clearing and the total number of hired workers.

The spatial data is stored in GIS using ArcView 3.2a whilst the non-spatial data is stored in MS Access $2000^{*}$. The non-spatial data is linked to the spatial layers through the Geocode. Both the MS Access 2000 and ArcView 3.2a systems are linked through Microsoft Open Database Connectivity (ODBC).

APMIS is implemented using the architecture as outlined in Figure 8. The system will be installed both at the WFW office in Futululu and at the Ratray office of Mondi in Kwam

\footnotetext{
* MS Access 2000 is a registered trademark Microsoft Corporation.
}

Bonambi. Each organisation will collect data relating to its operational area and the collected data will then be entered into the system. On a quarterly basis, all collected attribute data will be copied on to a CD and exchanged with the other organisations. This is most appropriate for now as the WFW office in Futululu does not have access to Internet connection though there is a telephone line.

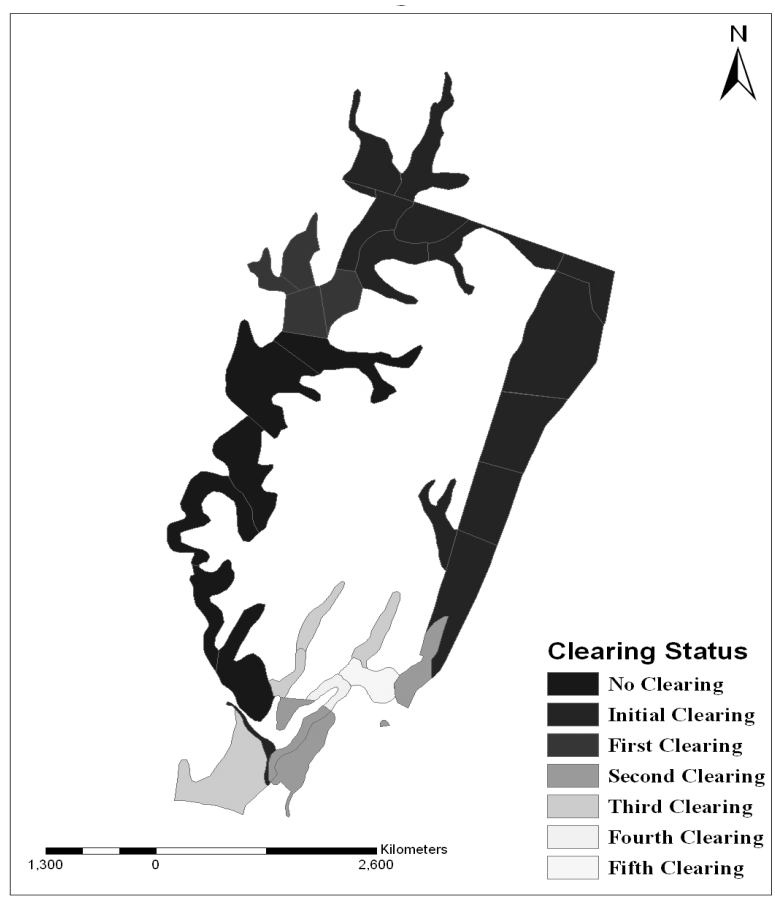

Figure 7. Eradication status.

Trained personnel will do the mapping of the newly in- 


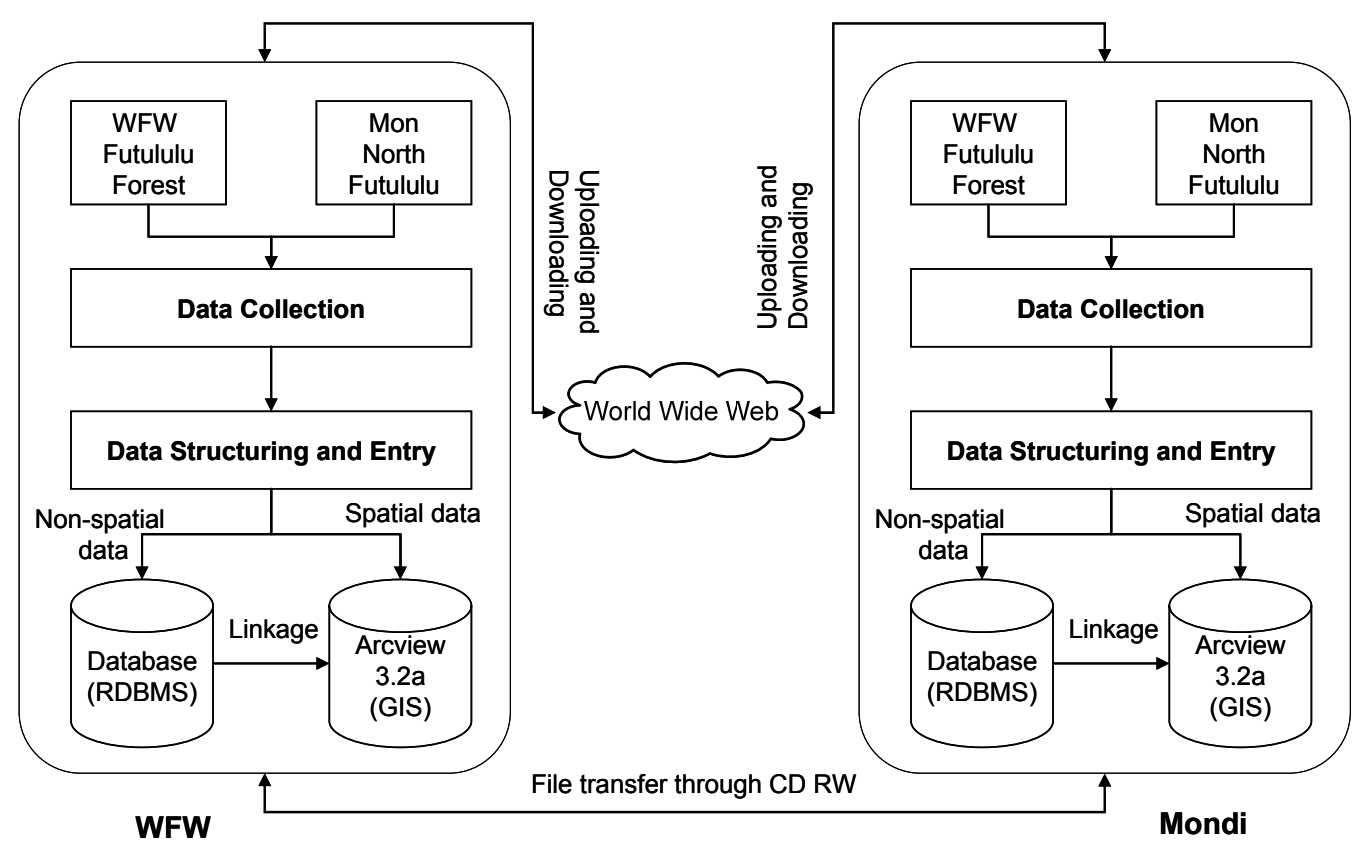

Figure 8. System architecture for prototype system implementation.

vaded areas, and the mapping methodology will be selected carefully in terms of the required time, skills, level of accuracy, equipment, cost implications and the nature of the terrain. With the necessary structures in place in both organizations, coupled with the nature of the terrain, field mapping with an ArcPad or a GPS is the best option. Mapping and the resultant spatial data will be accompanied with metadata on standard forms so that the data can be shared.

Trained personnel will also be involved in collecting the attribute data in the field. Attribute data will be collected on standard forms. Collection of attribute data on alien invasion will be done every three months, which coincides with the time intervals between successive treatments.

To introduce checks and balances, attribute data collected from the field will initially be put into a batch file and visually verified by an independent person who will check that all the mandatory fields are filled and their combination meaningful. The person will also check the attribute data against the previous data, and the treatment details of the Mapping Unit in a bid to remove any discrepancies.

Verified attribute data on alien plants invasion will then be passed to the GIS and Mapping Officer of WFW, or the silviculturist of Mondi depending on the location. Data will firstly be recorded in a replica database of APMIS and subjected to user defined and data structure integrity constraints. When the data have been found to be reasonably accurate, correct, complete, consistent and in the right format, then it will be entered into the main APMIS system. The data entry forms of APMIS have been designed to reduce the amount of data entry, thereby reducing errors such as wrong entry being made, or data redundancy.

With time, this architecture will be web enabled to allow managers to enter data in the field on species and density cover distribution, and the effects of treatments. With Internet facilities at both sites, a web-based data entry protocol will have to be developed, with off-line page reporting also developed for situations where the internet is down or non existent.

\section{Conclusions}

Through the development, adoption and adaptation of data formats, data exchange and user defined standards, a prototype system of Geographic Information System on alien plants invasion in the Wetland Park has been designed, tested and implemented. The system integrates multi-source data on invasive alien plant species from WFW and Mondi Limited based on common standards of data acquisition, representation and data exchange.

The prototype system is capable of providing information on extent and distribution of invasive alien plants, assess eradication status of mapped areas, information on new species becoming established in the area, and providing better understanding of how the distributional patterns and abundance of invasive alien plants change over space and time.

However, the prototype system covers only a few of the key players in the Heritage Site. A lot of functionalities are yet to be fully developed. At this stage, information on equipment, methods used and the costing for a clearing operation cannot 
be obtained from the system.

Assigning a Geocode made up of an NBAL Code and a time stamp provides a unique identification for each mapped unit, and a common data exchange standard. This coding standard does not only indicate which location and time a species was recorded but also ensures comparability over time on how the distribution and eradication represented by the number (level) of treatments was progressing. APMIS cannot only be used for the Greater St. Lucia Wetland Park but can also be used elsewhere in South Africa and other countries in order to get a broader picture of the extent and distribution of invasive alien plants based on common data standards. It can also be used in the areas of agricultural weed eradication programmes and in complex humanitarian environments where multiple organizations need to share data.

\section{References}

Drake, J.A., Mooney, H.A., di Castri, F., Groves, R.H., Kruger, F.J., Rejmanek, M. and Williamson, M. (1989). Biological Invasions: A Global Prospective SCOPE 37, John Wiley \& Sons, Chichester, pp. 437-461.

Groves, R.H. (1989). Ecological Control of Invasive Terrestrial Plants, in J.A. Drake, H.A. Mooney, F.D. Castri, R.H. Groves, F.J. Kruger, M. Rejmánek and M. Williamson (Eds.), Biological Invasions: A Global Perspective, John Wiley \& Sons, Chichester, pp. 437-461.

Higgins, S.I., Turpie, J.K., Costanza, R., Cowling, R.M., Le Maitre, D.C., Marais, C. and Midgley, G.F. (1997). An ecological economic simulation model of mountain fynbos ecosystems: Dynamics, valuation and management. Ecol. Econ., 22, 155-169.

Holmes, P.M. and Cowling, R.M. (1997). The effects of invasion by Acacia saligna on the guild structure and regeneration capabilities of South African fynbos shrublands. J. Appl. Ecol., 35(2), 317-332.

Le Maitre, D.C. and Versfeld, D.B. (1994). Field Manual for Mapping Populations of Invasive Plants for Use with the Catchment Management System, Report FOR-DEA, Department of Environment Affairs, Pretoria, South Africa.

Le Maitre D.C., Versfeld, D.B. and Chapman, R.A. (2000). The impact of invading alien plants on surface water resources in South Africa: A preliminary assessment. Water SA, 26(3), 397-408.

Macdonald, I.A.W., Kruger, F.J. and Ferrar, A.A. (1986). The Ecology and Management of Biological Invasions in Southern Africa, Oxford University Press, Cape Town, South Africa. .

McQueen, C. and Noemdoe, S. (2000). The working for water programme, in Best Management Practices for prevention and controlling Invasive Alien Species, Cape Town, South Africa.

Mack, R.N., Simberloff, D., Lonsdale, W.M., Evans, H., Clout, M. and Bazzaz, F. (2000). Biotic invasions: Causes, epidemiology, global consequences and control. Ecol. Appl., 10(3), 689-710.

Muniappan, R. and Marutani, M. (1996). Mechanical, cultural and chemical control of chromolaena odorata, in Proc. of the Fourth International Workshop on Biological Control and Management of Chromolaena odorata, Bangalore, India.

Myers, J.H., Simberloff, D., Kuris, A.M. and Carey, J.R. (2000). Eradication revisited: Dealing with exotic species. Trends in Ecol. Evol., 15(8), 316-320.

Nel, J.L., Richardson, D.M., Rouget, M., Mgidi, T.N., Mdzeke, N., Le Maitre, D.C., Van Wilgen, B.W., Schonegevel, L., Henderson, L. and Neser, S. (2004). A proposed classification of invasive alien plant species in South Africa: towards prioritizing species and areas for management action. S. Afr. J. Sci., 100, 53-64.

Richardson, D.M., Macdonal, I.A.W., Haffmann, J.H. and Henderson, L. (1997). Alien plant invasions, in R.M. Cowling, D.M. Richardson and S.M. Pierce (Eds.), Vegetation of Southern Africa, Cambridge University Press, Cambridge, pp. 535-567.

Richardson, D.M., Moranb V.C., Le Maitrec, D.C., Rougetd, M. and Foxcrofte, L.C. (2004). Recent developments in the science and management of invasive alien plants: Connecting the dots of research knowledge, and linking disciplinary boxes. S. Afr. J. Sci. (in press).

Stirton, C. (1978). Plant Invaders: Beautiful but Dangerous, Department of Nature and Environmental Conservation, Provincial Administration, Cape Town, South Africa.

Turlings, L. (2000). Invasive Plants and Animals: Is there way out?, Netherlands Committee for IUCN, Leiden.

UNEP (1994). Convention on biological diversity. Text and annexes. Geneva, Switzerland., The Interim Secretariat for the Convention on Biological Diversity.

UNEP, CBD and SBSTTA (2001). Invasive alien species: Case studies and country comments on invasive alien species. http://www.biodiv.org/doc/meetings/sbstta/sbstta-06/information/sbstta-06-inf-02-en.pdf.

UNESCO (1999). Report of the 23rd Session of the Committee. http://www.unesco.org/whc/sites/914.htm.

Usher, M.B. (1989). Ecological effects of controlling invasive terrestrial vertebrates, in J.A. Drake, H.A. Mooney, F. di Castri, R.H. Groves, F.J. Kruger, M. Rejmanek and M. Williamson, Biological Invasions: A Global Prospective SCOPE 37, John Wiley \& Sons, Chichester, pp. 463-489.

Van Wilgen, B.W., Little, P.M., Chapman, R.A., Görgens, A.H.M., Willems, T. and Marais, C. (1997). The sustainable development of water resources: History, financial costs, and benefits of alien plant control programmes. S. Afr. J. Sci., 93, 404-411.

WRI (1999). Mitigating the Impact of Alien/Invasive Species. http://www.wri.org/wri/biodiv/gbf/gbf13-02.htm. 